\title{
Fractura del maléolo tibial asociada con una luxación de tendones de la tibia posterior y del flexor común de los dedos: video demostrativo
}

\section{Tibial malleolus fracture associated with dislocation of posterior tibial and common flexor tendons of the fingers: demonstrative video}

Carlos Iván Andrade Aguilar,* Edgar Turrubiates Lucero,* Luis Gerardo Domínguez Gasca*

Hombre de 42 años, quien acudió a Urgencias, ya que 30 minutos antes de su llegada sufrió un traumatismo directo sobre la cara medial del tobillo izquierdo, que manifestaba dolor intenso e imposibilidad para la función. A la exploración física se detectó: discreto edema de tobillo y borde interno de pie izquierdo, sin flictenas, tobillo en eversión, con dolor intenso a la movilización pasiva y presencia de chasquido y deformidad de maléolo tibial; la sensibilidad y los pulsos fueron normales.

Se efectuaron radiografías anteroposterior y lateral del tobillo izquierdo (Figura 1), que corroboraron el diagnóstico de fractura del maléolo tibial correspondiendo a tipo 44-A1
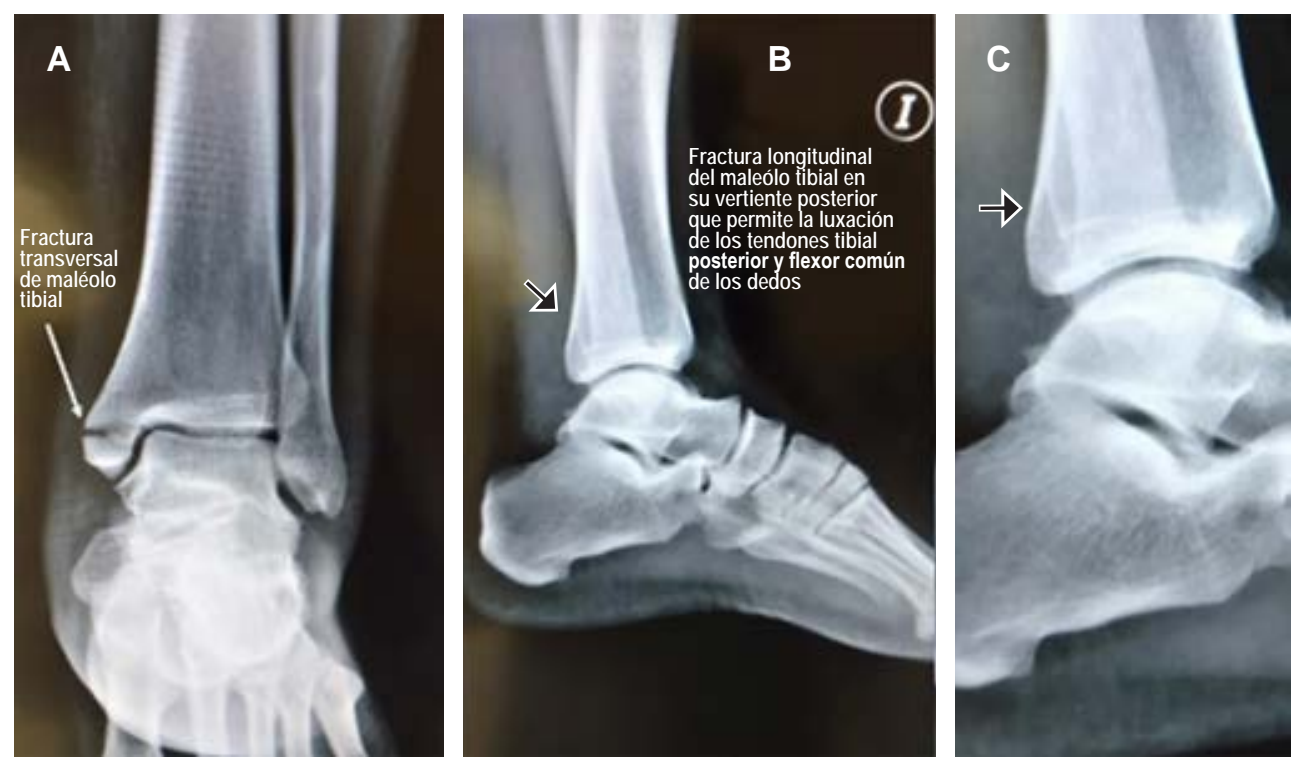

Figura 1: Radiografía anteroposterior. A) Lateral y del tobillo izquierdo que muestra una fractura transversa del maléolo tibial (flecha). B) Imagen lateral que evidencia una fractura longitudinal (aparentemente no desplazada) de la vertiente posterior interna del maléolo tibial (flecha negra). C) Acercamiento de la fractura (flecha negra).

\footnotetext{
* Traumatología-Ortopedia y Cirugía Articular. División de Cirugía del Hospital Ángeles León, León, Guanajuato. México.

Correspondencia:

Dr. Carlos Iván Andrade Aguilar

Correo electrónico: cuatotte@yahoo.com

Aceptado: 21-08-2019.
}

www.medigraphic.com/actamedica 
de la clasificación de OTA. Por ello, se decidió realizar una reducción abierta, encontrando una ruptura del ligamento anular interno del tarso y una luxación anterior de los tendones tibial posterior y flexor común de los dedos (Video 1). www.medigraphic.com/videos/actmed/am201z1
Posteriormente, se realizó la fijación maleolar por osteosíntesis, con colocación del tendón del tibial posterior y del flexor común de los dedos en el canal retromaleolar, y la reconstrucción del ligamento anular medial del tarso con fijación de fragmento fracturario longitudinal del maléolo medial. 